\title{
Depoimento [Do convívio com Jorge de Sena] ${ }^{1}$ Testimony [From the interaction with Jorge de Sena] \\ Fernando J. B. Martinho ${ }^{2}$
}

Resumo: Trabalhei durante três anos com Jorge de Sena na Universidade da Califórnia, Santa Bárbara, como leitor de Português. Na altura, já conhecia seu trabalho. A publicação da sua «3. ${ }^{a}$ Série» das Líricas portuguesas, em 1958, foi essencial para meu conhecimento da poesia portuguesa dos anos 30 a fins dos anos 50 . O convívio mantido com Sena contribuiu decisivamente para meu aprimoramento intelectual. Pessoa, dentre muitos outros autores do mundo lusófono, foi um dos principais temas de meus cursos e os ensaios de Sena sobre esse poeta muito ampliaram as minhas reflexões. A par disso, são inesquecíveis as visitas com a minha família à Randolph Road, onde sempre nos sentimos como em casa.

Palavras-Chaves: Jorge de Sena na Universidade da Califórnia e em família; Jorge de Sena professor; Jorge de Sena autor; Jorge de Sena leitor de Fernando Pessoa.

\begin{abstract}
I worked for three years with Jorge de Sena, at the University of California, Santa Barbara, as Lecturer in Portuguese. At the time I was already familiar with his work. The publication of the third series of Portuguese lyric, 1958, had been essential for my knowledge of Portuguese poetry from the 30 s to the late 50s. The intimacy with Sena contributed decisively to my intellectual development. Pessoa, among many other authors from the Lusophone world, was one of the main subjects of my courses, and Sena's essays on his poetry were a great help. I remember very fondly the frequent visits with my family to Randolph Road, where we always felt at home.
\end{abstract}

Keywords: Jorge de Sena at UCSB and at home; Jorge de Sena as a professor; Jorge de Sena as a writer; Jorge de Sena as a reader of Fernando Pessoa.

\footnotetext{
${ }^{1}$ Texto apresentado na Jornada Jorge de Sena, em 22 de janeiro de 2019, na Fundação Calouste Gulbenkian.

2 Faculdade de Letras, Universidade de Lisboa. Professor aposentado da Faculdade de Letras da Universidade de Lisboa, onde se doutorou em Literatura Portuguesa e lecionou no Departamento de Literaturas Românicas. Anteriormente, foi leitor de Português nas universidades de Bristol e de Santa Bárbara, Califórnia. Prémio Jorge de Sena pela publicação de Jorge de Sena: «Aqui no meio de nós», 2017.
} 
Como é bem sabido, trabalhei, durante três anos, como leitor de Português, com Jorge de Sena, na Universidade da Califórnia, em Santa Bárbara. E é essa a principal razão por que a Colóquio/Letras amavelmente me convidou para apresentar um depoimento na jornada de comemoração do centenário do escritor.

Quando cheguei à Califórnia em fins de agosto de 1974, tinha já um razoável contacto com a obra de Sena. E comecei pela leitura, em meados dos anos 50, em Lisboa, dos textos poéticos ou críticos que ele publicava nos mais importantes suplementos culturais de jornais da capital ou do Porto. Os artigos vindos a lume na imprensa diária, meio de comunicação que Sena sempre privilegiou por lhe permitir chegar a públicos mais amplos, cedo se tornaram, para mim, trabalhos de referência, pela profundidade com que os temas eram tratados e pela lucidez e largueza dos pontos de vista, colocando os nossos autores, quando eram eles que estavam em causa, em confronto com o que se passava noutros contextos histórico-culturais.

Em 1958, altura em que eu já ensaiava as primeiras incursões no ensaísmo literário, Sena

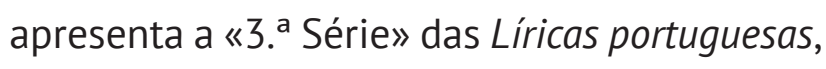
que ainda hoje é considerada uma das mais notáveis que entre nós se organizaram. Tinha, ali, uma arrumação crítica, de insuperável rigor, da poesia nacional das gerações de 40 e 50, bem como a justíssima recuperação de figuras que as antologias das duas séries anteriores tinham inexplicavelmente esquecido. À riqueza informativa e hermenêutica do prefácio, juntava Sena a pertinência e a inteligência da caracterização individual dos autores selecionados, nas notas crítico-biobibliográficas em que os apresentava, e que permaneceu, no essencial, válida, mesmo nos casos em que os autores deram natural prosseguimento às suas obras, às vezes em direções muito diversas das que inicialmente os moveram.

Nesse mesmo ano de 1958, publicaria ele Fidelidade, um dos seus títulos maiores, a inaugurar uma coleção, a Círculo de Poesia da Moraes, que viria a incluir alguns dos seus livros subsequentes. Era a consagração da sua grande poesia, se é que o não fora já a publicação de As evidências: Poema em vinte $e$ um sonetos, na Coleção Cancioneiro Geral do Centro Bibliográfico, em 1955. Fidelidade foi lido pela minha geração - os que, então, andavam à volta dos 20 anos - com entusiasmo e com o mesmo encantamento com que, folheando a «3. ${ }^{a}$ Série» das Líricas portuguesas, tivera a revelação extasiada de textos e autores. Reproduzo, do livro da Moraes, um dos mais conhecidos poemas de Sena, e de manifesto teor político, «Quem a tem...», de 1956:

\footnotetext{
Não hei de morrer sem saber qual a cor da liberdade.

Eu não posso senão ser desta terra em que nasci. Embora ao mundo pertença e sempre a verdade vença,
} 
qual será ser livre aqui,

não hei de morrer sem saber.

Trocaram tudo em maldade,

é quase crime viver.

Mas, embora escondam tudo

e me queiram cego e mudo,

não hei de morrer sem saber

qual a cor da liberdade.

De data anterior,concretamente de 1951, e dado à estampa no $n .^{\circ} 2$ da revista $A$ Serpente, era, no florilégio da Portugália Editora, o celebérrimo «Uma pequenina luz», de não menor intenção política, embora possa alargar-se-lhe o sentido da esperança que nele procura incutir-se e cuja luz teimosamente brilha e não esmorece.

O poema As evidências contém, na edição original, um «Prefácio» que, surpreendentemente, Sena não reproduziu quando incluiu o livro em Poesia-I, de 1961, e acerca do qual escreve, justificando a sua presença na edição de 1955:

É evidente que não pretendi nem pretendo, nestas linhas, explicar os vinte e um sonetos, cuja diversidade estrófica foi para mim uma garantia da individualizada autenticidade de cada um. Não porque tema os censores que se horrorizam ante o espetáculo de um poeta explicando-se a par e passo. Muitos, e dos maiores, o fizeram melhor que seus exegetas.

Atente-se bem na última frase da passagem transcrita. Está aqui explicado, preto no branco, no seu amargo humor, o que seria o frequente recurso a prefácios e posfácios em futuras obras.

No ano em que saiu Poesia-l, na Moraes, publicou Jorge de Sena, na editora que era a que se encarregara de divulgar a obra de Pessoa, desde 1942, uma segunda coletânea de ensaios, $O$ poeta é um fingidor, em que se incluía um texto que sempre prezei muito entre os não poucos que dedicou ao criador do «drama em gente». 0 pequeno volume da Ática, comprei-o, então, e foi interessante relê-lo agora, passados tantos anos, e reparar no que diligentemente tinha sublinhado. Intitulava-se o referido ensaio «Vinte e cinco anos de Fernando Pessoa», e com ele assinalara Sena, no suplemento literário de 0 Estado de S. Paulo, nos fins do ano anterior, o extraordinário acontecimento que fora a publicação no Brasil da Obra poética de Fernando Pessoa, organizada, com inexcedível desvelo e exemplar apuro, por Maria Aliete Galhoz. Não há quem não conheça e se não tenha deliciado com o incipit do célebre ensaio: «Minha tia-avó, Virgínia Sena Pereira, irmã de meu avô paterno...». A história é sabida e eu não vou, agora, por manifesta falta de tempo, relembrá-la. Diga-se apenas que Sena, muito jovem, conhecera na casa da sua familiar que muito estimava, e que habitava no n. ${ }^{\circ} 16,1 .^{\circ}$ esq., da rua Coelho da Rocha, um «senhor suavemente simpático, muito bem vestido, que escondia no beiço de cima o riso discretamente casquinado», e que lhe parecia «muito velho», com a sua «calvície, os olhos gastos, o jeito 
de sentar-se com as mãos nos joelhos, e uma voz velada», que habitava no andar em frente do de D. Virgínia. Um pouco à frente do passo citado, conclui Sena, com lúcida ironia, que «afinal, e à semelhança de tantos que hoje se vangloriam de o ter conhecido, [não chegou] a conhecer Fernando Pessoa», para, logo a seguir, acrescentar uma daquelas verdades que nunca devem esquecer-se:

\footnotetext{
$E$ aqueles que efetivamente o conheceram, será que o conheceram melhor? E será que, para conhecer-se o poeta que ele foi é necessário conhecer tudo isso? E tudo isso não é, afinal, fora das congeminações terríficas em que o espírito dele se abismava lucidamente, e que o levavam a intervenções tão na aparência abstrusas e escandalosas, uma biografia sem biografia?
}

Com esta última formulação, «uma biografia sem biografia», Sena antecipava-se um ano ao tão falado início de um ensaio que foi decisivo na internacionalização da obra de Pessoa, «Fernando Pessoa: El desconocido de sí mismo», de Octavio Paz: «Los poetas no tienem biografía. Su obra es su biografía».

Permitam-me que, antes de encerrar este depoimento, eu me refira ainda a um outro texto de Jorge de Sena sobre Pessoa, que, mais concretamente, é constituído pelas respostas que deu a três perguntas de Luciana Stegnano Picchio, destinadas ao número inicial de Quaderni Portoghesi, relativo à primavera de 1977, e que é, todo ele, uma magistral lição do eminente comparatista que Sena era, antes de tais estudos se cimentarem entre nós, como veio a acontecer, nas últimas décadas. A questão que me interessa sublinhar, neste texto, a da tão debatida questão da sinceridade em poesia, é uma questão conexa à levantada na passagem que acima citei. Deixo-a aqui, sem mais delongas:

\begin{abstract}
A única sinceridade dum poeta não é ser ele-mesmo, outro, ou muitos outros, confessando uma real vida que lhes tenha acontecido: a única sinceridade de um poeta é dedicar-se a ouvir o universo, e a dizê-lo tão bem quanto possível, independentemente de ser quem é [...]. Tal como na vida, somos quem nos fazemos ou quem assumimos ser, ou quem aceitamos que nos mandem ser.
\end{abstract}

Este texto, afinal, bem unitário, embora subdividido em três respostas, foi escrito em Santa Bárbara em março de 1977, o ano em que eu iria regressar a Portugal, acompanhado de minha mulher e minha filha. Foram esses três anos que vivi na Califórnia decisivos na minha formação intelectual, e, aí, teve um papel de grande relevância Jorge de Sena, pelo seu exemplo, pelo seu magistério, pela sua estima e pela sua amizade. Sobretudo me marcou muito a confiança que em mim, desde o princípio, depositou, entregando-me tarefas bem exigentes, e a que procurei responder com o melhor que tinha para dar. Na casa da Randolph Road, encontrámos sempre um acolhimento caloroso, e tivemos a experiência 
inesquecível de um convívio enriquecedor, a que frequentemente se juntavam colegas da universidade ou amigos das filhas do casal, em animadas conversas sobre tudo o que se possa imaginar dentro da ilimitada variedade da vida e da arte. Serões que mantemos bem vivos na nossa grata memória, sob a luminosa generosidade de Jorge e Mécia de Sena.

\section{Bibliografia}

Paz, O. (1961). Fernando Pessoa: El desconocido de sí mismo. Revista de la Universidad de México. 3: 4-7;

Sena, J. de. (1955). As evidências: Poema em vinte e um sonetos. Centro Bibliográfico. Lisboa; Sena, J. de. (1958). Fidelidade: Poemas. Livraria Morais. Lisboa;

Sena, J. de. (1961a). Poesia-I. Morais. Lisboa;

Sena, J. de. (1961b). Vinte e cinco anos de Pessoa. Em: O poeta é um fingidor. Ática. Lisboa;

Sena, J. de. (1977). Jorge de Sena risponde a tre domande su Pessoa. Quaderni Portoghesi. 1: 137-148. 